\title{
Creating a backscatter multispectral mosaic with the R2Sonic 2024 Echosounder
}

\section{Creación de un Mosaic multiespectral de retrodispersión con la Ecosonda R2Sonic 2024}

AGUILAR-RAMIREZ, Ana María, GONZALEZ-JUAREZ, Aníbal, MOLINA-NAVARRO, Antonio and UTRERA-ZARATE, Alberto

Instituto Oceanográfico del Golfo y Mar Caribe

ID $1^{\text {st }}$ Author: Ana María, Aguilar-Ramírez / ORC ID: 0000-0003-2867-8254, CVU CONACYT ID: 811392

ID $1^{\text {st }}$ Co-author: Aníbal, González-Juárez / ORC ID: 0000-0002-7012-5277, CVU CONACYT ID: 1003848

ID $2^{\text {nd }}$ Co-author: Antonio, Molina-Navarro / ORC ID: 0000-0001-7949-8371, CVU CONACYT ID: 811437

ID $3^{\text {rd }}$ Co-author: Alberto, Utrera-Zarate / ORC ID: 0000-0002-6282-4449, CVU CONACYT ID: 365626

DOI: 10.35429/EJT.2021.9.5.24.31

Received March 22, 2021; Accepted June 11, 2021

\begin{abstract}
The backscatter in Hydrographic surveys (LH) at the time of bathymetry is to measure the response of the acoustic pulse upon reaching the seabed, one part is reflected and another is absorbed by the type of sediment that exists on the bottom, the main objective The purpose of this work is to create a multispectral mosaic with the Broadband Multibeam Echosounder (MBES) R2Sonic 2024, in order to characterize the seabed through the use of different frequencies $(170 \mathrm{kHz}, 330 \mathrm{KHz}$ and $450 \mathrm{kHz})$. Therefore, bathymetric data were obtained from the hydrographic survey carried out in the Port of Veracruz, highlighting that only one area of the seabed of said Port was analyzed, starting from the cleaning of the data with Hypack, the creation of the reference surface with the Fledermaus software and finally the backscatter data processing with the FMGeocoder Toolbox software. The processing allowed us to obtain as a final product a backscatter multispectral mosaic with acceptable parameters (due to the missing information of the $330 \mathrm{kHz}$ frequency, but it was replaced by the $200 \mathrm{kHz}$ one), which signify the beginning of the implementation of these mosaics in This area of research with multiple hydrographic, oceanographic and geological applications, due to the fact that currently there are not many studies on this subject in Mexico.
\end{abstract}

Mosaic, Multispectral, Backscatter

\begin{abstract}
Resumen
La retrodispersión en los Levantamientos Hidrográficos (LH) al momento de realizar la batimetría es medir la respuesta del pulso acústico al llegar al fondo marino, una parte se refleja y otra es absorbida por el tipo de sedimentos que existe en el fondo, el objetivo principal del presente trabajo es crear un Mosaic multiespectral con la Ecosonda Multihaz de Banda Ancha (MBES) R2Sonic 2024, con el fin de caracterizar el fondo marino mediante el uso de diferentes frecuencias $(170 \mathrm{kHz}, 330 \mathrm{KHz}$ y 450 $\mathrm{kHz}$ ). Por lo anterior se obtuvieron datos batimétricos del levantamiento hidrográfico realizado en el puerto de Veracruz, resaltando que se analizó solo una zona del fondo marino de dicho Puerto, iniciando desde la limpieza de los datos con Hypack, la creación de la superficie de referencia con el software Fledermaus y finalmente el procesamiento de los datos de retrodispersión con el software FMGeocoder Toolbox. El procesamiento nos permitió obtener como producto final un Mosaic multiespectral de retrodispersión con parámetros aceptables (debido a que faltó información de la frecuencia de $330 \mathrm{kHz}$, pero se reemplazó por la de $200 \mathrm{kHz}$ ), que significan el inicio de la implementación de estos mosaicos en esta área de investigación con múltiples aplicaciones hidrográficas, oceanográficas y geológicas, debido a que actualmente no existe en México muchos estudios sobre este tema.
\end{abstract}

Mosaic, Multiespectral, Retrodispersión

Citation: AGUILAR-RAMIREZ, Ana María, GONZALEZ-JUAREZ, Aníbal, MOLINA-NAVARRO, Antonio and UTRERA-ZARATE, Alberto. Creating a backscatter multispectral mosaic with the R2Sonic 2024 Echosounder. ECORFAN Journal-Taiwan. 2021. 9-5: 24-31

\footnotetext{
* Author's Correspondence (marianaram1305@ hotmail.com)

$\dagger$ Researcher contributing as first author.
} 


\section{Introduction}

Backscatter or Backscatter measures the intensity of the reflection of the acoustic frequency of the seabed, determined by the beam angle (R2 SONIC, 2029), the main characteristic of this backscatter multispectral mosaic is based on its possibility of supporting the In efforts to characterize the types of seabed, using different acoustic wavelengths, backscatter mosaic analysis has the following applications: assessment of the seabed, characteristics of the seabed such as hardness, monitoring of marine constructions due to changes over time, detection and verification of objects, exploration of natural resources, as well as habitat delimitation for research purposes.

All multibeam echo sounders have the kindness of determining the depth of the seabed by calculating the travel time of the pulses emitted by the transducer and received by it, the reflection of the pulse will depend on the emitted frequency, the angle of incidence and the background response. Hard bottoms reflect the signal better than soft bottoms, because soft bottoms absorb the energy received. (Ballesteros Mora \& García Sala, 2010).

Derived from the problem of knowing the seabed, using information from multibeam systems, the creation of a backscatter multispectral mosaic for the analysis of the seabed was carried out with information from the multibeam echo sounder R2Sonic 2024, which has been part of the research teams of the Oceanographic Institute of the Gulf and Caribbean Sea, but the creation of the aforementioned mosaics had not yet been implemented.

To create the backscatter multispectral mosaic, it was necessary to use the mosaics of each frequency $170 \mathrm{kHz}, 330 \mathrm{kHz}$ and $450 \mathrm{kHz}$, obtained with the information collected by the R2Sonic 2024 echo sounder, using the FMGeocoder Toolbox (FMGT) software, used for backscatter processing. The investigation of the creation and implementation of the backscatter multispectral mosaic was carried out in the interest of knowing more about the characterization and classification of the seabed.
In the methodology for the creation of the backscatter multispectral mosaic, a series of processes were carried out in different softwares (Hypack, fledermaus and FMGT) with the data acquired inside the port of Veracruz, during the development of the processing the collected data was analyzed, Said information allowed us to obtain as a final result a multispectral mosaic with acceptable parameters (due to the lack of information on the $330 \mathrm{kHz}$ frequency, but it was replaced by that of $200 \mathrm{kHz}$ ).

This research has a benefit in the academic field, because it is the basis for knowing more about the aforementioned topic, it also provides institutional benefits because the backscatter multispectral mosaic means a new product that can be implemented in the direction of hydrography with information from the characteristics of the seabed.

The objective of backscattering in Hydrographic Surveys ( $\mathrm{LH}$ ) at the time of bathymetry is to measure the response of the acoustic pulse upon reaching the seabed, one part is reflected and another is absorbed by the type of bottom with which it makes contact (Carreño, 2009). So all the multibeam echo sounders, in addition to allowing us to determine the depth of the seabed, have also been able to generate various bathymetric products, such as bathymetric surfaces and the backscatter mosaic (grayscale image), in addition to the Nautical Chart $(\mathrm{CN})$ that Until now it was the final product made by the Secretary of the Navy (SEMAR).

Among the equipment available to the Hydrographic Survey Brigades (BLH) at the Oceanographic Institute of the Gulf and the Caribbean Sea, there is the multibeam echo sounder R2 SONIC 2024 that, unlike the other multibeam echo sounders, not only mediates a frequency, but also They allow measurements with up to three simultaneous frequencies, which allowed us to generate a backscatter multispectral mosaic. With the backscatter mosaic generated by the returned energy snippets (fragments), it is possible to achieve an analysis for the characterization of the seabed (Craig J., Jonathan Beaudoin, Mike Brissette, \& Vicki Gazzola, 2019), quoted mosaic allows to perform an analysis of the seabed, and to be the basis of various hydrography, oceanography, and research projects, among other sciences with oceanic interests. 


\section{Methodology}

For the preparation of this research, a bathymetric data processing was carried out in accordance with the coverage standards of the established fund (OHI, 2008) on October 29, 30, 31,2019 , said information was acquired in the vicinity of the port of Veracruz according to the study area of Figure 1, with the R2Sonic 2024 echo sounder according to the characteristics of Table 1 .

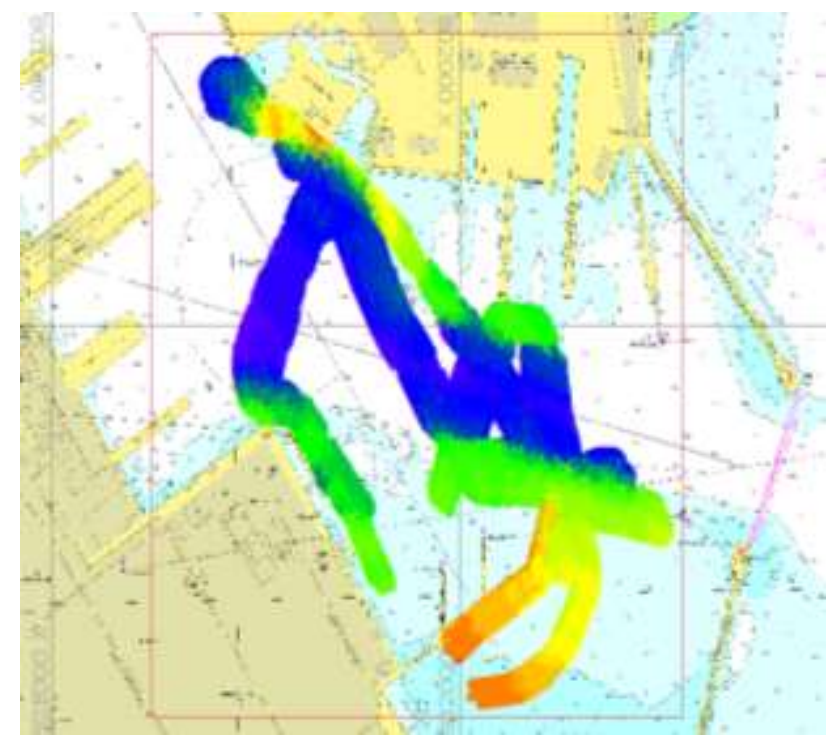

Figure 1 Study area

Source: Hypack (2020)

The multibeam echo sounder, R2Sonic 2024, has the following characteristics:

\begin{tabular}{|l|l|}
\hline \multicolumn{1}{|c|}{ System caracteristics } & \multicolumn{1}{c|}{ Specification } \\
\hline Frequency & $400 \mathrm{kHz} / 200 \mathrm{kHz}$ \\
\hline $\begin{array}{l}\text { Beam width - across } \\
\text { sweep }\end{array}$ & $\begin{array}{l}0.5^{\circ} @ 400 \mathrm{kHz} / 1.0^{\circ} @ 200 \\
\mathrm{kHz}\end{array}$ \\
\hline $\begin{array}{l}\text { Beam width - along the } \\
\text { sweep }\end{array}$ & $\begin{array}{l}1.0^{\circ} @ 400 \mathrm{kHz} / 2.0^{\circ} @ 200 \\
\mathrm{kHz}\end{array}$ \\
\hline Number of beams & 256 \\
\hline Sweep angle & $10^{\circ}$ to $160^{\circ}$ (user selection) \\
\hline Pulse length & $15 \mu$ Sec- $1000 \boldsymbol{\mu}$ Sec \\
\hline Pulse type & $\begin{array}{l}\text { Continuous } \\
\text { (CW) }\end{array}$ \\
\hline Depth range & $\begin{array}{l}100 \text { meters }(3000 \text { meters } \\
\text { optional) }\end{array}$ \\
\hline Operating temperature & $-10^{\circ} \mathrm{C}$ to $40^{\circ} \mathrm{C}$ \\
\hline Storage temperature & $-30^{\circ} \mathrm{C}$ to $55^{\circ} \mathrm{C}$ \\
\hline
\end{tabular}

Tabla 1 R2 Sonic 2024 Echosounder Specification System

Source: R2 Sonic Operation Manual, 2024



Figure 2 Shows the R2Sonic 2021 Echosounder and modular interface and technical data modes



Figure 2 R2Sonic 2021 echo sounder and modular interface

Source: R2 Sonic 2024 Operation Manual (2019)

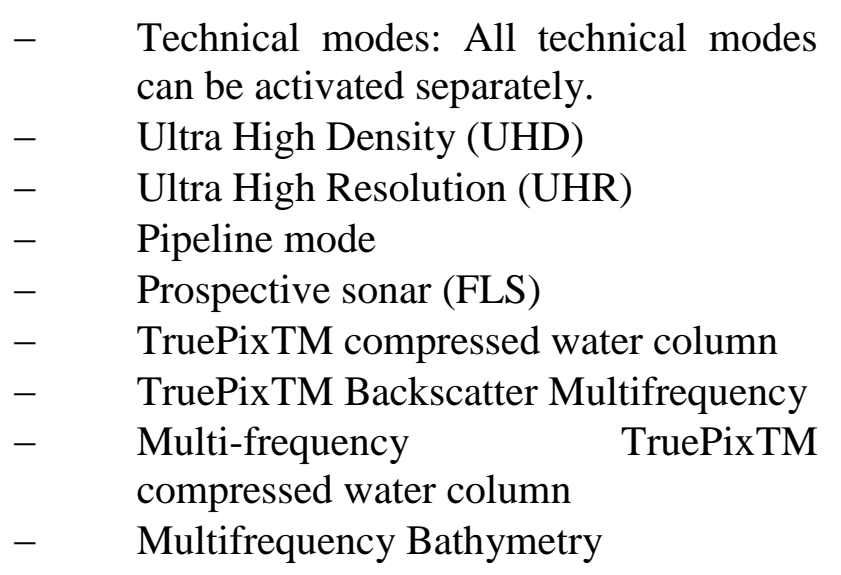

Once the post-processing of the bathymetric data had been carried out and the bathymetric surface was generated in Figure 3 grid format, custom configurations were created for the frequencies of $170 \mathrm{kHz}, 330 \mathrm{kHz}$ and 450 $\mathrm{kHz}$ according to Figure 4, since these frequencies are the necessary ones. To elaborate the backscatter multispectral mosaic, due to the quality of the data collected, a processing was configured for the $200 \mathrm{kHz}$ mosaic, which will be explained later. 


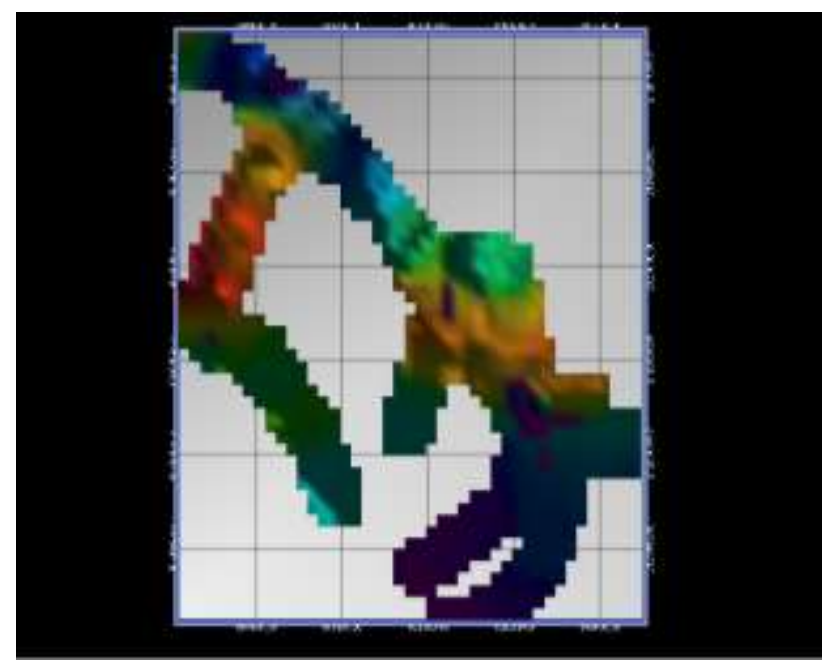

Figure 3 Grid-format bathymetric surface Source: Fledermaus 7.0 (2020)

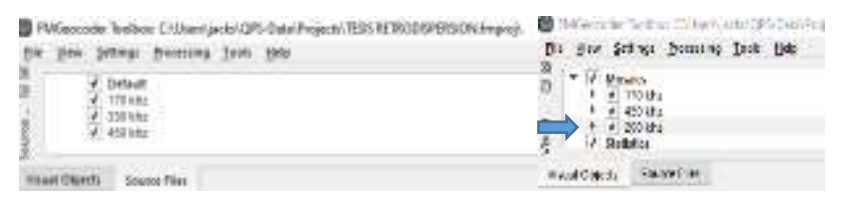

Figure 4 Render Settings for Tiles Source: FGMT V.7.8.10 (2020)

In the case that the absorption has not been added for each frequency in Sonic control, it is possible to add the absorption information in the 'settings' within the processing parameters for the given frequency, as in the data collected this absorption was applied during the acquisition no value had to be applied in the FMGT tool.

\section{Mosaic generation for each band:}

If mosaics of each frequency measured simultaneously are created, it allows the possibility of identifying an acoustic response for each band according to the type of sediment. Collecting backscatter data in multi-frequency increases the uniformity and precision of the measured data.

$170 \mathrm{kHz}$ : The reference grid (Gridded data) must be activated, all GSF files must be selected, and in the multispectral processing parameters it is limited to a single frequency 170 kHz Figure 5.



Figure 5 Frequency limit

Source: FGMT V.7.8.10(2020)
Afterwards, it was checked that the mosaic memory was green before starting the processing, if it was red, the mosaic size would be updated, for example $2.5 \mathrm{~m}$., Then we select "Automatic Processing - Beam Time Series" a window will appear pop-up that shows the steps and progress of the backscatter mosaic processing of Figure 6.

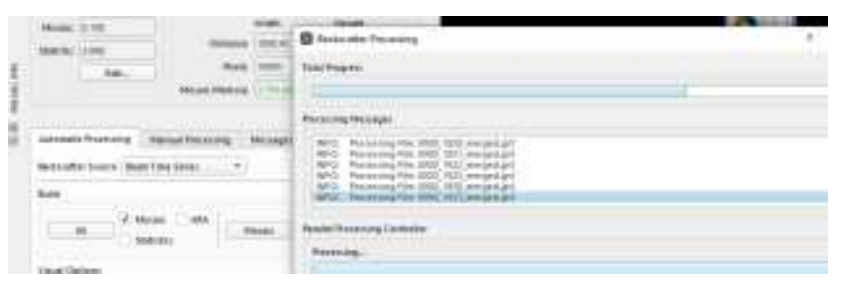

Figure $6170 \mathrm{kHz}$ processing

Source: FGMT V.7.8.10(2020)

The time it takes to process the mosaic is related to the number of source files, the set pixel size, the cores of the computer, and the processing power, at the end of the process the mosaic is reflected on the main screen of objects visuals, in this part the name corresponding to the mosaic frequency " $170 \mathrm{kHz}$ " was added.

The range of the color scale can be adjusted to improve the contrast within the mosaic, this was done on the histogram.

To generate the following mosaics, the previous mosaic was deselected, the indexed files were refreshed since the data was collected simultaneously and therefore the GSF merge file is the same base.

Finally the steps were repeated for the other frequencies, in this way we obtained the $170 \mathrm{kHz}, 200 \mathrm{kHz}$ and $450 \mathrm{kHz}$ mosaics, the 330 $\mathrm{kHz}$ mosaic was not created due to a failure to estimate the resolution range according to Figure 7.



Figure 7 Processing Error $330 \mathrm{kHz}$ Source: FGMT V.7.8.10 (2020) 
This happened because at the time of acquisition no snippets (fragments) were collected at said frequency, adding a $200 \mathrm{kHz}$ mosaic that has a few snippets to be able to generate the backscatter multispectral mosaic. After processing the individual files were exported in grayscale GeoTiff format (Image). mosaic.

Creating the backscatter multispectral

Multispectral mosaic (RGB) processing uses 3 mosaics, the red channel at $170 \mathrm{kHz}$, the green channel at $330 \mathrm{kHz}$ replaced by the 200 $\mathrm{kHz}$, and the blue channel at $450 \mathrm{kHz}$.

\section{Results and analysis}

The representation was carried out through graphs that have an octagonal shape, where each side of the geometric Figure represents one of the components of the wind. Each of these sides is the base of a bar graph where it represents the monthly average of the frequency of the wind and the color, based on the Beaufort scale (Table 2 ), indicates the maximum average sustained wind that can be expected. . Likewise, in the central part it is shown if there was no wind, a situation known as periods of calm.

From the special order survey carried out on October 30, 2019, 10 navigation lines were taken, later the processing for cleaning bathymetric data and indexing was carried out and the procedure to generate the $170 \mathrm{kHz}, 200$ $\mathrm{kHz}$ and 450 mosaics was added. $\mathrm{KHz}$, in order to create a backscatter multispectral mosaic of the study area, as shown in Figure 1.

Multibeam systems have advanced to high levels, that now we can achieve a high resolution mapping of the seabed, for that 3 different frequencies were needed to be able to appreciate how absorption reacts according to the different sediments found on the seabed, The mosaics generated for $170 \mathrm{KHz}$ (Figure 8), $200 \mathrm{kHz}$ (Figure 9), $450 \mathrm{KHz}$ (Figure 10) and the backscatter multispectral mosaic (Figure 11) are shown first.

\section{Mosaic 170 kHz}

We can visualize that in said mosaic information was collected with the $170 \mathrm{KHz}$ frequency uniformly from Figure 8, verifying the gain saturation parameters, this is one of the mosaics that are needed to generate the multispectral.

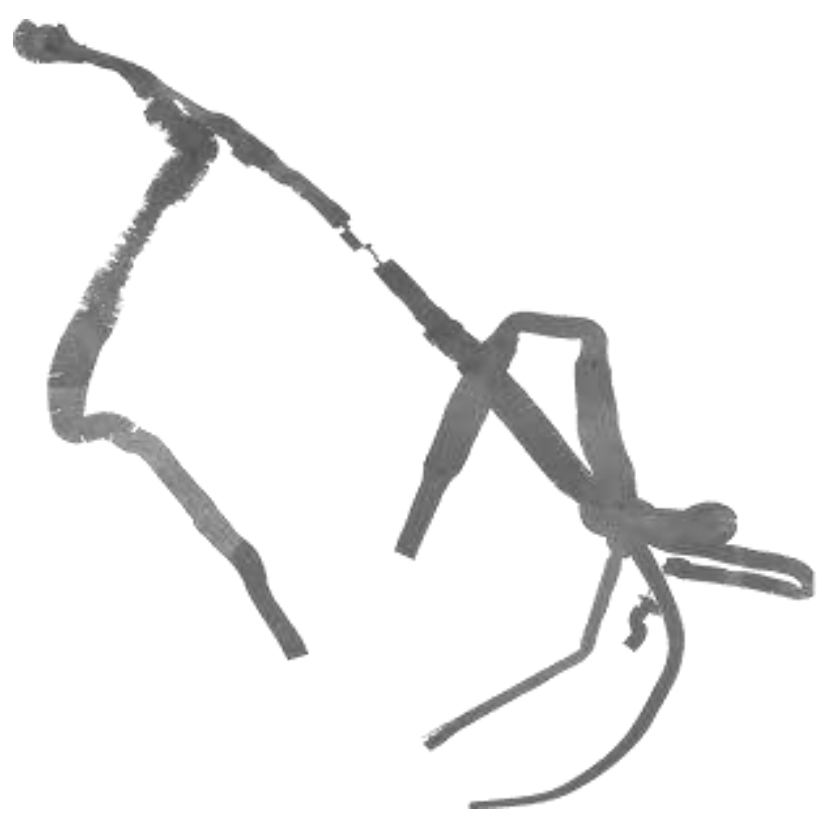

Figure 8 Mosaic $170 \mathrm{kHz}$

Source: FGMT V.7.8.10 (2020)

Mosaic 200 kHz

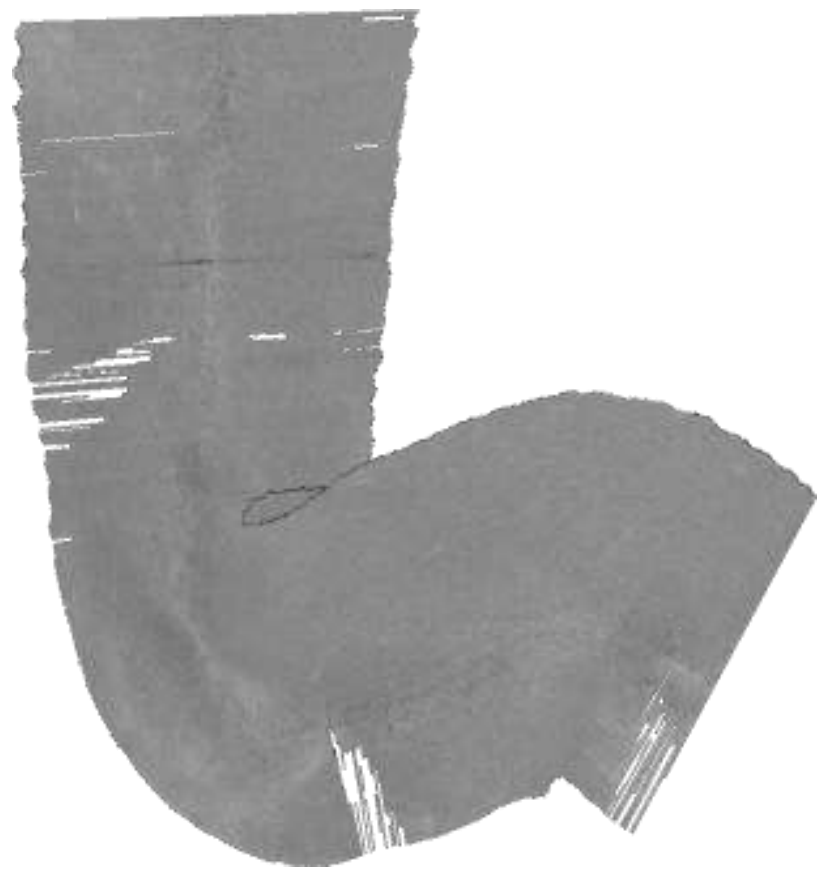

Figure 9 Mosaic $200 \mathrm{kHz}$

Source: FGMT V.7.8.10 (2020)

The second Mosaic was carried out using the $200 \mathrm{kHz}$ frequency (Figure 9), replacing the $330 \mathrm{kHz}$ frequency for which no data was collected (they were necessary to obtain better results), we can analyze that the information was not collected in a uniform, therefore the Mosaic does not cover the total area of the survey, although little information was used to generate the final Mosaic. 


\section{Mosaic 450 kHz}

For the generation of the third backscatter Mosaic, the $450 \mathrm{kHz}$ frequency was used (Figure 10), analyzing the Mosaic obtained we note that it only covers $70 \%$ of the total survey area, it contains more information than the $200 \mathrm{kHz}$ one, but it will be necessary to generate the final Mosaic.



Figure 10 Backscatter Multispectral Mosaic Source: FGMT V.7.8.10 (2020)

This Mosaic is used to analyze the seabed, it gives us a better perception to analyze the sediments on the bottom, it is created with the mixture of frequencies $170 \mathrm{kHz}$ (red), $330 \mathrm{kHz}$ (green) and $450 \mathrm{kHz}$ (blue), in In this case, the $170 \mathrm{kHz}$ frequency was replaced by the $200 \mathrm{kHz}$ one that had some data, the methodology to create the multispectral Mosaic was achieved (Figure 11), but in subsequent studies the collection should be considered uniformly in each of them, with this a better result will be obtained.

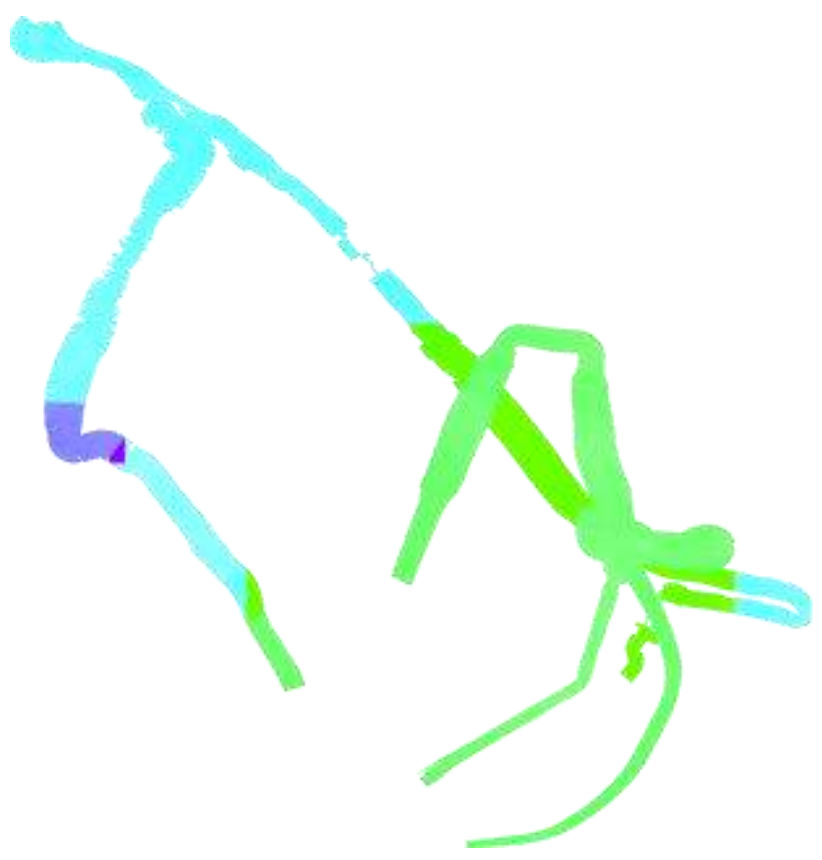

Figure 11 Backscatter Multispectral Mosaic (RGB) Source: FGMT V.7.8.10 (2020)

\section{$170 \mathrm{kHz}, 200 \mathrm{kHz}$ and Multispectral Analysis (RGB)}

We can analyze that the response of the seabed sediments changes from one frequency to another (Figure 12), but in the RGB we can notice the seabed delimited by borders (grouping of similar sediment traits), in this case the frequency was used of $200 \mathrm{kHz}$ due to the absence of data of the $330 \mathrm{Khz}$ frequency, in (Figure 13) an area that coincides with the other frequencies was analyzed and a better perception is appreciated in the RGB.

The result is acceptable as it forms a basis for future research in the field of backscattering for the analysis of the seabed.

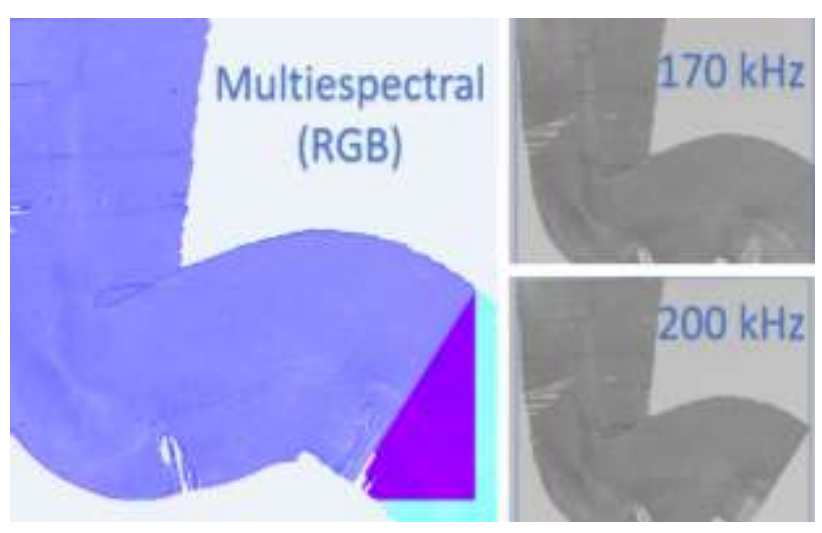

Figure 12 Boundary delimitation Source: Microsoft 365 (2020) 




Figure 13 Analyzed Area

Source: Microsoft 365 (2020)

\section{Mosaic Hypack Geocoder}

To complement the backscatter information we add a Mosaic generated in Geocoder Hypack license software, where we can see another way of using the information of a backscatter Mosaic, in this case it is only done with a frequency and in probabilistic absorption data measured in decibels, a type of bottom sediment, called "Sandy Clay" is generalized for the study area see Figure 14.



Figure 14 Mosaic Geocoder

Source: Hypack (2020)

\section{Conclusions}

In this work, the principle and characteristics of backscatter were described, focusing only on the data collected with the R2Sonic 2024 echo sounder, the most important of which is the innovation that backscatter mosaics bring with them in the analysis of the seabed.
It was understood how the R2Sonic 2024 echo sounder works in the acquisition of the bathymetric data necessary to generate the backscatter Mosaic, the most outstanding thing is that said echo sounder allows to generate a multispectral Mosaic merging the 3 spectral bands; red, green and blue $(170 \mathrm{kHz}, 330 \mathrm{kHz}$, $450 \mathrm{kHz}$ ), what was difficult in this case was the absence of data on the $330 \mathrm{kHz}$ frequency, which is why it was replaced by the $200 \mathrm{kHz}$ to generate the multispectral Mosaic.

In the aforementioned work, a backscatter multispectral Mosaic was created step by step, the most important thing was the processing in different softwares to obtain the files necessary for the creation of the multispectral Mosaic.

The creation of the backscatter multispectral Mosaic was achieved with the R2Sonic 2024 echo sounder, only a part of the seabed of the study area was analyzed, because in the acquisition it was necessary to collect data at the $330 \mathrm{kHz}$ frequency, however, it is the principle to obtain information on the seabed while performing the bathymetry.

\section{Recommendations}

In the areas where special order surveys (S-44) are carried out using the R2Sonic 2024 echo sounder, activate the acquisition of truepix multifrequency data, to generate the backscatter multispectral mosaics and have a better understanding of the seabed.

The key to a good backscatter mosaic lies in good data acquisition, which is why the hydrographer must monitor the saturation levels of each frequency during this process.

Multispectral Distropersion Mosaic has the advantage of reducing the costs of traditional surveys that require multibeam data at various frequencies in addition to increasing productivity and providing other products of multispectral bathymetry for the characterization of the seabed that serve as a basis for the investigation of other areas such as oceanography and geology.

\section{References}

Ballesteros Mora, L., \& García Sala, D. (2010). Estudios Batimétricos con Ecosonda Multihaz y clasificación de fondos. 
Carreño, F. (2009). Aplicación de Análisis Textural a datos de retrodispersión de sonda multihaz Teledetección.

Craig J., B., Jonathan Beaudoin, Mike Brissette, \& Vicki Gazzola. (2019). Multiespectral Multibeam Eco Sounder Backscatter as a Tool Improved Seafloor Characterization. Geosciencies.

Herzfeld, D. (1993). Atlas of antartica. Colorado U.S.A.

OHI. (2008). Normas de la OHI para los Levantamientos Hidrográficos publicación $S$ 44. Mónaco: Bureau Hidrográfico Internacional.

OHI. (2010). Normas de la OHI para los Levantamientos Hidrográficos publicación $C$ 13. Mónaco: Bureau Hidrográfico Internacional. R2 SONIC. (2019). Multispectral Backscatter. HYPACK. (2021).

Hypack.https://www.hypack.com/File\%20Libra ry/Resource\%20Library/Manuals/2021/HYPA CK-2021-User-Manual_SP.pdf

Quality Positioning Services. (2020). Manual de Referencia Fledermaus User Interface. QPS. https://confluence.qps.nl/fledermaus7/reference -manual/fledermaus/fledermaus-user-interface

R2Sonic. (2021, 23 julio). Multibeam Echosounder (MBES) Case Studies. https://www.r2sonic.com/case-studies/

Casco Antiguo. (2019). Catálogo de productos 2019 oceanografía $e$ hidrografía. https://www.cascoantiguo.com/public/mailing/o ceanografia/catalogo/catalogo_cascoantiguo_oc eanografia_america_2019.pdf?utm_source=Sen derglobal\&utm_campaign=Seminario $+\mathrm{NKE}+\mathrm{ch}$ ile\&utm_medium=email 